\title{
Flora da Bahia: Rhizophoraceae
}

\author{
Lucas Cardoso Marinho $^{1 *}$, Reyjane Patrícia de Oliveira $^{1, a}$ \& Ana Maria Giulietti ${ }^{1,2, b}$ \\ 1 Programa de Pós-Graduação em Botânica, Departamento de Ciências Biológicas, Universidade Estadual de \\ Feira de Santana, Feira de Santana, Bahia, Brasil. \\ 2 Royal Botanic Gardens, Richmond, United Kingdom.
}

\begin{abstract}
Resumo (Flora da Bahia: Rhizophoraceae) - É apresentado o levantamento florístico de Rhizophoraceae da Bahia, Brasil, como uma contribuição ao conhecimento da flora do Estado. É reconhecida apenas Rhizophora mangle, espécie bem distribuída nas áreas de manguezal. São apresentadas descrições da família, gênero e espécie, bem como ilustração, mapa de distribuição geográfica e comentários sobre a espécie.
\end{abstract}

Palavras-chave adicionais: florística, Malpighiales, manguezal, Nordeste brasileiro, Rhizophora.

\begin{abstract}
Flora of Bahia: Rhizophoraceae) - This account of the Rhizophoraceae is a further contribution on the ongoing Flora of Bahia project. Only Rhizophora mangle, a widely distributed species in the mangrove areas, was recognized in the state. Description of the family, genus and species as well as illustration, distribution map and general comments on the species are presented.

Additional key words: floristic, Malpighiales, mangrove, Northeastern Brazil, Rhizophora.
\end{abstract}

\section{RHIZOPHORACEAE}

Árvores ou arbustos, com rizóforos ou não; tricomas simples. Folhas opostas ou verticiladas, simples, margens crenadas ou serreadas a inteiras, pecioladas, peninérveas; estípulas interpeciolares, geralmente com coléteres na superfície abaxial. Inflorescências cimosas, axilares; brácteas na base ou na porção central do pedúnculo; bractéolas presentes. Flores actinomorfas, uni ou bissexuadas; sépalas 3-5 ou muitas, conatas, carnosas ou coriáceas; pétalas 3-5 ou muitas, livres, geralmente com tricomas; prefloração valvar; estames 8,10 ou muitos; filetes livres ou conatos na base, curtos ou completamente ausentes; anteras introrsas ou extrorsas, rimosas, raramente com muitos loci; disco nectarífero geralmente presente; ovário súpero ou ínfero, 2- ou 6locular, 1-8 óvulos por lóculo, placentação axilar; estigmas lobados a sublobados. Fruto cápsula septicida ou baga; sementes 1 a muitas, ariladas ou não, vivíparas ou não.

Pertencente à ordem Malpighiales, Rhizophoraceae é considerada monofilética, bem como cada uma das suas três tribos (Macarisieae, Gynotrocheae e Rhizophoreae). É apontada como grupo-irmão de Erythroxylaceae (Setoguchi et al. 1999; APG II 2003; APG III 2009).

Possui 16 gêneros e cerca de 150 espécies com distribuição predominantemente pantropical (Stevens 2014). No Brasil, ocorrem quatro gêneros e 10 espécies: Cassipourea Aubl. inclui três espécies das Regiões Norte e Nordeste (Maranhão); Paradrypetes ilicifolia Kulm., que foi descrita em Euphorbiaceae e

\footnotetext{
*Autor para correspondência: 1cmarinho1@gmail.com;

arpatricia.oliveira@gmail.com; banagiulietti@hotmail.com

Editor responsável: Alessandro Rapini

Submetido: 19 nov. 2014; aceito: 15 dez. 2014

Publicação electrônica: 20 dez. 2014; versão final: 23 dez. 2014
}

recentemente transferida para Rhizophoraceae, ocorre no Espírito Santo e Minas Gerais; Sterigmapetalum Kuhlm. inclui duas espécies das Regiões Norte e Centro-Oeste (Mato Grosso); e Rhizophora L. inclui três espécies dos mangues das Regiões Norte, Nordeste e Sudeste (Mansano et al. 2014). Apesar de abundante em áreas de manguezais tropicais, a família não é exclusiva deste ambiente (Hogarth 2007).

\section{Rhizophora L.}

Árvores ou arbustos vivíparos, com rizóforos. Folhas opostas ou verticiladas, margens crenadas ou serreadas a inteiras, pouco revolutas; estípulas interpeciolares geralmente caducas, coléteres na superfície abaxial. Inflorescência com brácteas na porção central do pedúnculo; bractéolas formando um tubo na base da flor. Flores bissexuadas; sépalas 4, 5 ou muitas, persistentes; pétalas 4 , geralmente com tricomas; estames 8 ou muitos; filetes muito curtos ou ausentes; anteras introrsas; ovário ínfero, 2-locular, 1 óvulo por lóculo; estigmas 2; disco nectarífero presente. Fruto baga; semente 1, arilada ou não.

Rhizophora possui cerca de 10 espécies distribuídas pantropicalmente em áreas costeiras do Oceano Atlântico, costa americana do Pacífico, alcançando algumas ilhas do oeste do Pacífico (Duke \& Allen 2006; Spalding et al. 2010). No Brasil, ocorrem três espécies de Rhizophora: $R$. harrisonii Leechm e R. racemosa G. Mey, restritas ao Pará e Maranhão, e R. mangle L., de ampla distribuição (Mansano et al. 2014). A Bahia possui cerca de 110.000 ha de áreas de manguezal (Vanucci 1999) dominadas por Rhizophora mangle.

\subsection{Rhizophora mangle L., Sp. Pl. 1: 443. 1753.}

Figuras 1-3.

Árvores ou arbustos até $7 \mathrm{~m}$ alt.; internós 8,5-12 $\mathrm{cm}$ compr.; rizóforos lignificados, arqueados, parcialmente submersos. Folhas $7-10 \times 3,7-5,2 \mathrm{~cm}$, 
agrupadas no ápice dos ramos, coriáceas, discolores, lanceoladas a oblongas, ápice obtuso, margem inteira, base atenuada a decorrente, face adaxial verde-escura, sem pontuações, face abaxial mais clara, com pontuações negras; pecíolo 1,5-2 cm compr., verde. Inflorescências 2-floras; pedúnculo 2,5-4 cm compr.; ráquis 1,2-2 cm compr.; botão floral 1,2-2 cm compr., cônico; brácteas 2, suborbiculares a triangulares, verdes; bractéolas 2, 1-1,5 mm compr., suborbiculares, verdes. Flores tetrâmeras; sépalas 4, 9-10 × 3-3,5 mm, amarelo-esverdeadas, triangulares, ápice agudo, margem inteira, base truncada, glabras, quilhadas na face abaxial; pétalas, 6,5-8 × 2-2,5 $\mathrm{mm}$, alvas, oblongas a lineares, ápice agudo, margem inteira, base truncada, face abaxial pubescente, tricomas simples, alvos; estames 8, 3-4 mm compr., livres, amarronzados, glabros; disco nectarífero anelado; ovário ca. $4 \mathrm{~mm}$ compr.; estigmas 2, sésseis. Frutos 2 $2,5 \times 0,8-1,2 \mathrm{~cm}$, ovoides, verdes passando a castanhos quando maduros.

Rhizophora mangle é amplamente distribuída nas áreas de manguezal do Brasil, ocorrendo desde o Pará até Santa Catarina (Mansano et al. 2014). D10, E9, E10, F8, F9, G8, H8, H9, I8, J8. Simpátrica a $R$. harrisonii e $R$. racemosa nos estados do Pará e Maranhão, $R$. mangle difere de ambas por apresentar inflorescências bifloras, enquanto as outras duas espécies apresentam inflorescências com três a oito flores (Duke \& Allen 2006). Rhizophora mangle floresce entre os meses de dezembro e julho e frutifica entre janeiro e outubro.

Material selecionado - Belmonte, $15^{\circ} 51^{\prime} \mathrm{S}, 38^{\circ} 52^{\prime} \mathrm{W}, 14 \mathrm{fev}$ 2003 (est.), M.L. Guedes \& D.M. Loureiro 10172 (ALCB); Cairu, $13^{\circ} 29^{\prime} \mathrm{S}, 39^{\circ} 02^{\prime} \mathrm{W}, 27$ jan. 1982 (fr.), Y. Moema s.n. (ALCB 10952, CEPEC) Camaçari, Barra do Jacuípe, $12^{\circ} 41^{\prime} \mathrm{S}$, $38^{\circ} 39^{\prime} \mathrm{W}, 6$ nov. 1994 (fr.), E. Melo et al. 1120 (HUEFS); Camamu, rio Amba, $13^{\circ} 56^{\prime} \mathrm{S}, 39^{\circ} 06^{\prime} \mathrm{W}, 25$ jan. 2001 (bot.), E.A. Rocha et al. 666

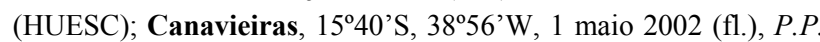
Oliveira et al. 39 (HUEFS); Caravelas, Manguezal de Alcobaça, $15^{\circ} 40^{\prime} \mathrm{S}, 38^{\circ} 59^{\prime} \mathrm{W}, 5$ maio 2002 (fl.), P.P. Oliveira et al. 103 (HUEFS); Conde, Comunidade de Cobó, $11^{\circ} 53^{\prime} \mathrm{S}, 37^{\circ} 35^{\prime} \mathrm{W}, 1 \mathrm{mar}$ 2008 (bot.), C.T. Andrade 50 (HUEFS); Entre Rios, fazenda Sauípe, $11^{\circ} 56^{\prime} \mathrm{S}, 38^{\circ} 05^{\prime} \mathrm{W}, 25$ fev. 1986 (est.), M. Campos 28 (ALCB); Ilhéus, foz do rio Cachoeira, $14^{\circ} 48^{\prime} \mathrm{S}, 39^{\circ} 02^{\prime} \mathrm{W}, 5$ abr. 2007 (fl.), F.B. Matos 1342 (CEPEC); Itanagra, Porto de Sauípe, $12^{\circ} 15^{\prime}$ S, $38^{\circ} 02^{\prime} \mathrm{W}, 15$ jun. 1975 (fl.), G.C.P. Pinto s.n. (ALCB

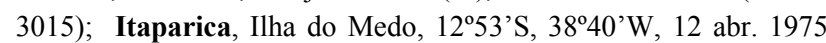
(fr.), A.L. Costa s.n. (ALCB 3013); Jaguaripe, $13^{\circ} 06^{\prime} \mathrm{S}, 38^{\circ} 53^{\prime} \mathrm{W}$, 2011 (fr.), P. Costa s.n. (ALCB 99232); Jandaíra, próximo às

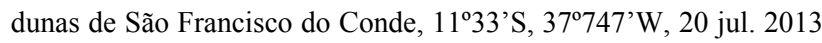
(fl.), M.L. Guedes et al. 21010 (ALCB); Maraú, Ponta do Mutá, $14^{\circ} 06^{\prime} \mathrm{S}, 39^{\circ} 00^{\prime} \mathrm{W}, 5$ fev. 1979 (fr.), S.A. Mori et al. 11400 (CEPEC); Mata de São João, Sauípe, $12^{\circ} 31^{\prime} \mathrm{S}, 38^{\circ} 17^{\prime} \mathrm{W}, 25$ fev. 1986 (fr.), H.P. Bautista \& G.C.P. Pinto 1041 (ALCB, CEPEC,

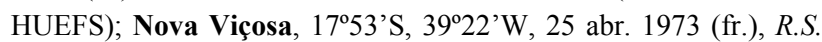
Pinheiro 2133 (CEPEC, RB); Porto Seguro, Rio do Peixe ou rio Itanhem, 16 $26^{\prime}$ 'S, 39 $09^{\circ} \mathrm{W}, 20$ mar. 1974 (fl. e fr.), R.M. Harley 17206 (CEPEC); Prado, 17016'S, 39¹1'W, 1 dez. 1997 (fl.), M. Fonseca \& M.L. Guedes 1070 (ALCB, CEPEC); Salvador, Baía de Aratu, $12^{\circ} 58^{\prime}$ S, $38^{\circ} 30^{\prime} \mathrm{W}, 11$ jan. 1982 (fr.), Y.M. Leite s.n. (ALCB
22888); Santa Cruz Cabrália, Mata Costeira, $16^{\circ} 16^{\prime} \mathrm{S}, 39^{\circ} 01^{\prime} \mathrm{W}$, 31 out. 1966 (fr.), R.P. Belém \& R.S. Pinheiro 2809 (CEPEC); Simões Filho, Área do Belov, 1246'S, 38 $26^{\circ}$ 'W, 20 maio 2002 (fr.), L.J. Alves et al. 427 (ALCB); Una, Acuípe, 1505'S, 39 04'W, 22 maio 2003 (fr.), E.A. Rocha 1104 (HUESC); Vera Cruz, Salinas das Margaridas, 1257'S, 38³6'W, 6 set. 1999 (est.), M.L. Guedes et al. 6447 (ALCB).

A variação encontrada na espécie, principalmente no que diz respeito ao tamanho e comprimento das folhas e rizóforos, está diretamente ligada à maior frequência de inundação (Fig. 3G) e níveis de salinidade (Macnae 1968). Existe também a influência latitudinal, sendo que o desenvolvimento máximo de $R$. mangle ocorre próximo à linha do Equador (SchaefferNovelli 1995), havendo pequena redução da altura em direção aos limites tropicais (Grasso et al. 1995). Tal variação pode ser percebida nos espécimes provenientes da Bahia, devido à longa extensão da costa do Estado. Os espécimes com origem no litoral norte possuem maior porte e folhas mais crassas do que os indivíduos do litoral sul.

\section{AgRADECIMENTOS}

Aos curadores dos herbários ALCB, CEPEC, HRB, HUEFS e RB, pelo acesso às coleções; à FAPESB, pelo auxílio financeiro ao Projeto Flora da Bahia, (APR0162/2007); ao CNPq, pelo apoio ao PROTAX (Proc. 562278/2010-9), ao projeto Flora da Bahia (483909/2012) e ao Reflora (Proc. 563548/2010-0), bem como pelas bolsas de Mestrado para LCM e Produtividade em Pesquisa para RPO (PQ2) e AMG (PQ1-A); a Alex Popovkin, Ivan Abreu e Ezeilda Marinho, pelas fotografias.

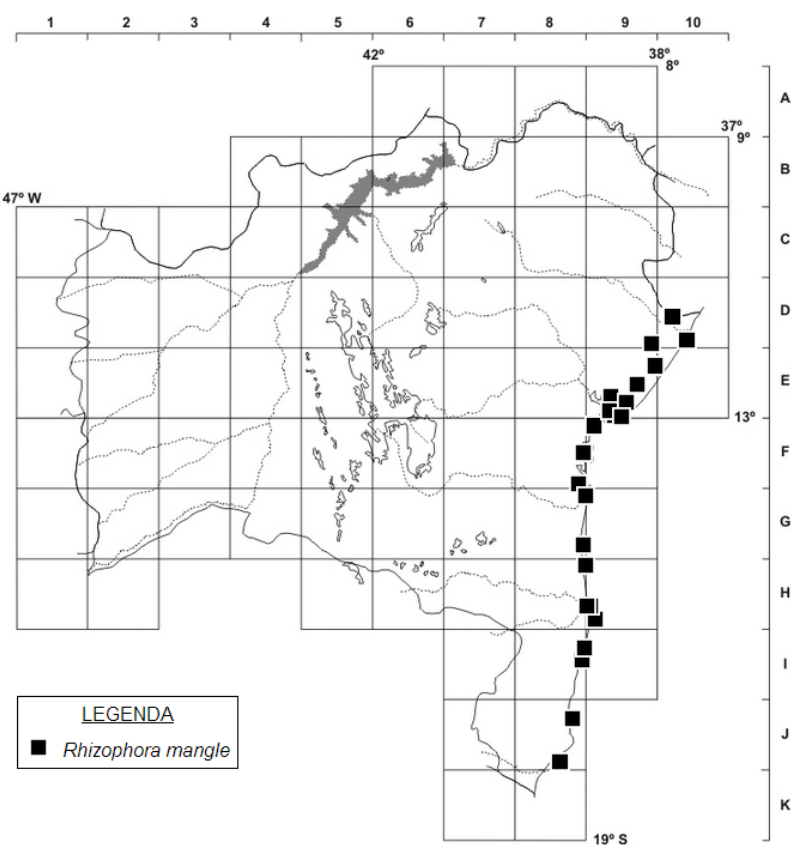

Figura 1. Distribuição geográfica de Rhizophora mangle no estado da Bahia. 

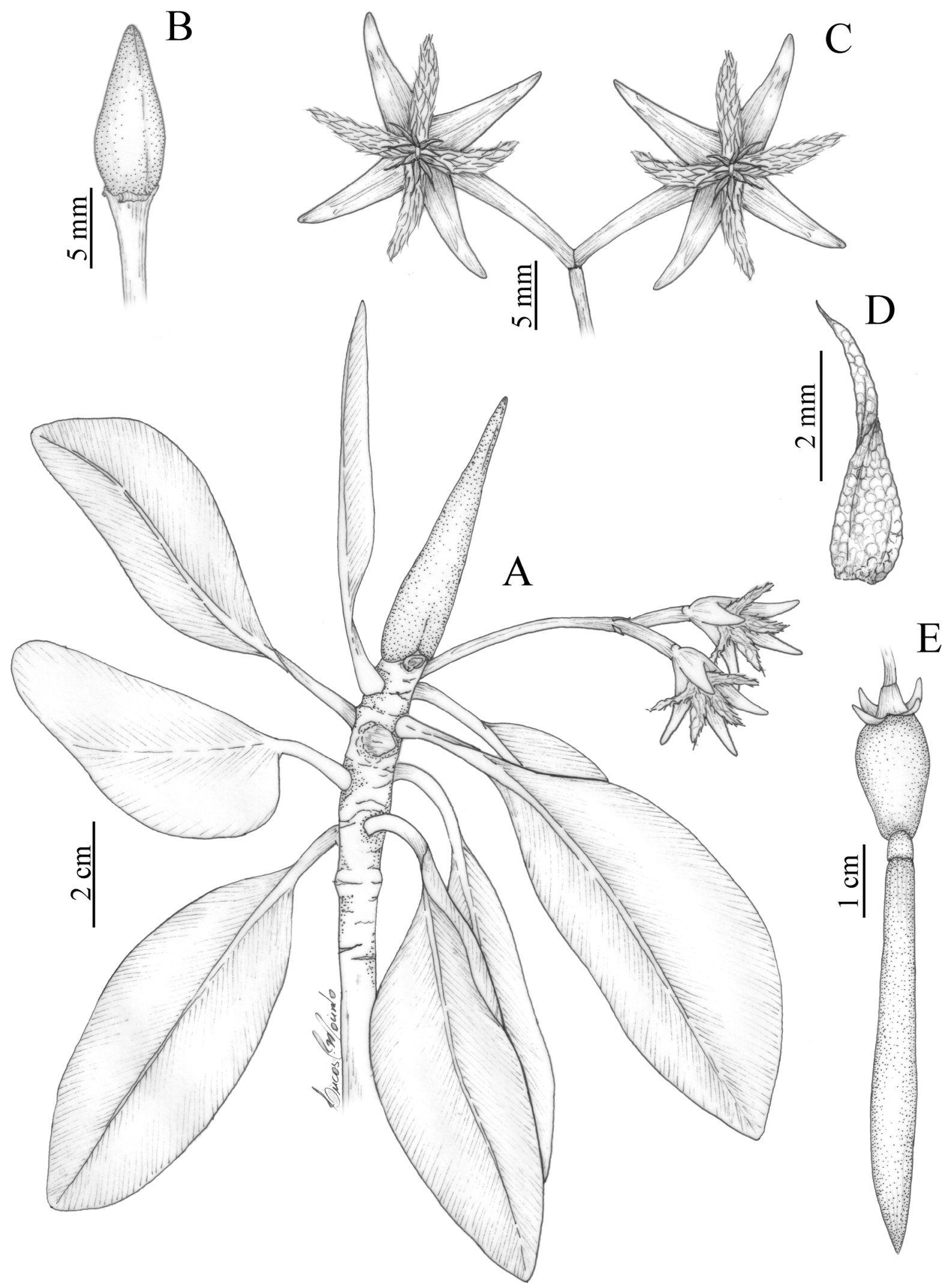

Figura 2. Rhizophora mangle: A- ramo com flores; B- botão floral; C- inflorescência; D- estame; E- fruto germinando (A-D, F- Oliveira 103; E- Popovkin 182). 

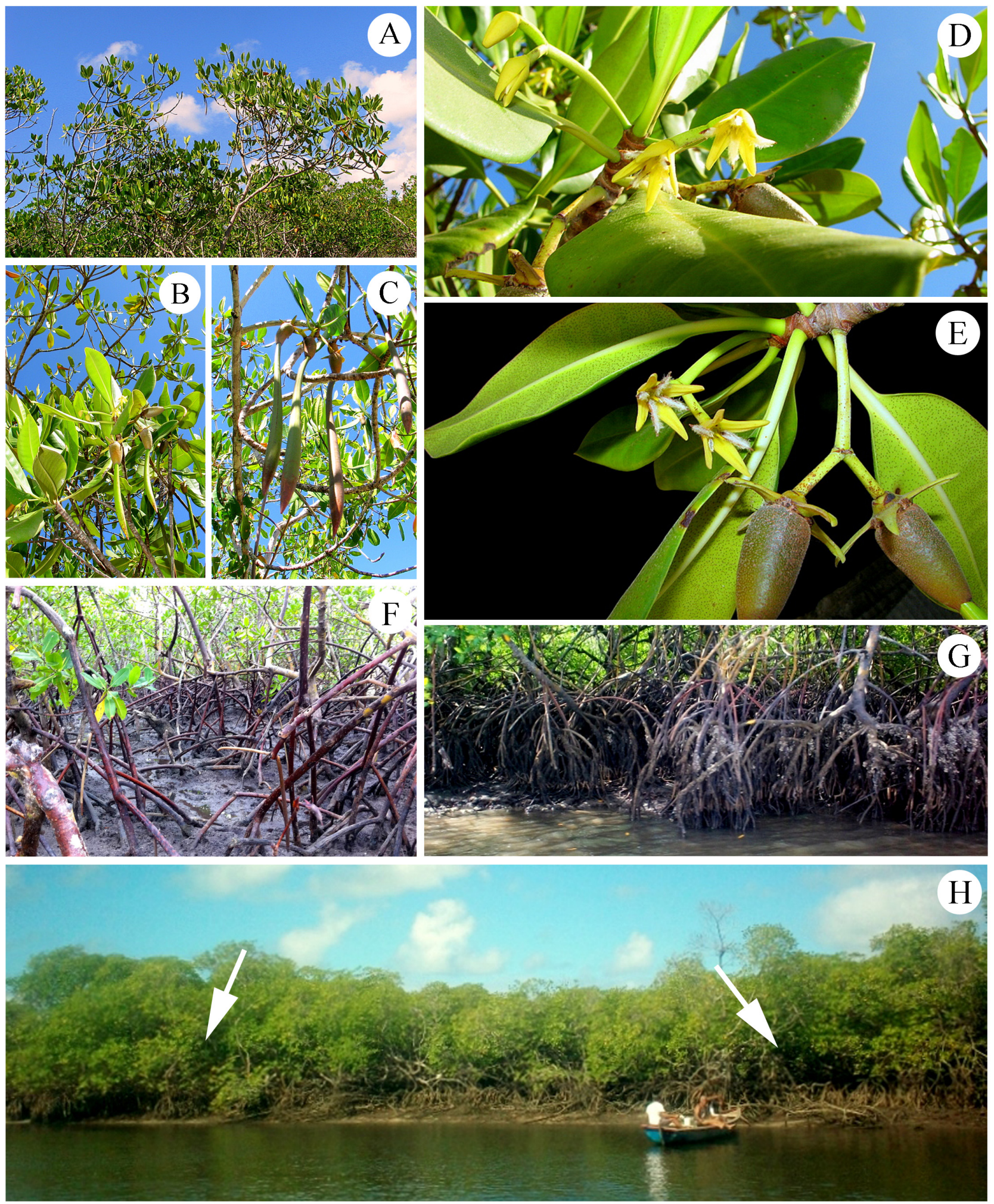

Figura 3. Rhizophora mangle: A- aspecto geral; B- ramo com flores e frutos germinando; C- ramo com frutos germinando; D- ramo com botões florais e flores; E- ramo com flores e frutos jovens; F- pneumatóforos em área lamosa; G- pneumatóforos parcialmente submersos; H- formações de R. mangle. (fotos: A-E- A. Popovkin; F- I.S. Abreu; G-H- E. Marinho).

\section{REFERÊNCIAS}

APG II. 2003. An update of the Angiosperm Phylogeny Group classification for the orders and families of flowering plants: APG II. Botanical Journal of the Linnean Society 141: 399-436.
APG III. 2009. An update of the Angiosperm Phylogeny Group classification for the orders and families of flowering plants: APG III. Botanical Journal of the Linnean Society 161: 105121.

Duke, N.C. \& Allen, J.A. 2006. Rhizophora mangle, R. samoensis, $R$. racemosa, $R . \times$ harrisonii (Atlantic-East Pacific red 
mangrove). In: Species Profiles for Pacific Island Agroforestry. Versão 2.1. Disponível em http://www.traditionaltree.org; acesso em 11 dez. 2014.

Grasso, M.; Tognella, M.M.P.; Schaeffer-Novelli, Y. \& Comune, A.E. 1995. Aplicação de técnicas de avaliação econômica ao ecossistema manguezal. In: P.H. May (org.), Economia Ecológica: aplicação no Brasil. Campus, Rio de Janeiro, p. 49-81.

Hogarth, P.J. 2007. The Biology of Mangroves and Seagrasses. Oxford University Press, New York.

Macnae, W. 1968. Zonation within mangroves associates in North Queensland. In: G.H. Lauff (ed.), Estuaries. American Association for the Advancement of Science, Camberra, p. 432441.

Mansano, V.F.; Barros, L.A.V. \& Assunção, V.A. 2014. Rhizophoraceae. In: Lista de Espécies da Flora do Brasil. Jardim
Botânico do Rio de Janeiro. Disponível em http://reflora.jbrj.gov.br/ jabot/floradobrasil/FB208; acesso em 13 jul. 2014.

Schaeffer-Novelli, Y. 1995. Manguezal Ecossistema entre a Terra e o Mar. Caribbean Ecological Research, São Paulo.

Setoguchi, H.; Kosuge, K. \& Tobe, H. 1999. Molecular phylogeny of Rhizophoraceae based on $r b c L$ gene sequences. Journal of Plant Research 112: 443-455.

Spalding, M.; Kainuma, M. \& Collins, L. 2010. World Atlas of Mangroves. Earthscan, London.

Stevens, P.F. 2014. Angiosperm Phylogeny Website. Version 12, July 2012 [and more or less continuously updated since]. Disponível em http://www.mobot.org/MOBOT/research/ APweb/; acesso em 10 jul. 2014.

Vanucci, M. 1999. Os Manguezais e Nós: uma síntese de percepções. EDUSP, São Paulo.

\section{LISTA DE EXSICATAS}

Alves, L.J. 427; Andrade, C.T. 50; Bautista, H.P. 1041; Belém, R.P. 2384, 2809; Campos, M. 28; Costa, A.L. s.n. ACLB 3012, ALCB 3013, ALCB 3014; Costa, P. s.n. ALCB 99232; Fonseca, M. 1070; Guedes, M.L. 396, 1033, 1068, 1307, 6447, 10172, 11289, 11489 , 14585, 16945, 19335, 21010, 21130, s.n. ALCB 27765, ALCB 26368; Harley, R.M. 17206; Jesus, N.G. 1506; Leite, Y.M. s.n. ALCB 22888; Matos, F.B. 1342; Mattos-Silva, L.A. 883; Melo, E. 1120, 1122; Moema, Y. s.n. ALCB 10097, ALCB 10952; Mori, S.A. 11400; Nascimento, I. s.n. ALCB 8256, ALCB 8257; Oliveira, P.P. 39, 103; Pinheiro, R.S. 2133; Pinto, G.C.P. s.n. ALCB 3015; Popovkin, A.V. 181, 182; Rigueira, D. s.n. ALCB 67936; Rocha, E.A. 666, 1104, 1174; Santana, W. s.n. ALCB 21116, ACLB 23389, ALCB 27738; Sicupira, P.R. 10; Silva, D.S. 1. 